\title{
The Influences of Self-Esteem \& Ego in Our Daily Lives
}

\author{
Prabhakararao Sampthirao ${ }^{1 *}$
}

\section{ABSTRACT}

One of the most deceptive aspects of the ego is that it generates powerful emotional reactions, the trail of emotional reactions that ego leaves behind are anger at a loved one, a need to be right, a feeling of insecurity in certain situations, feelings of unexplained jealousy, the need to impress someone, and so on. Conflictual behavior at workplace not only impacts those who are involved in the conflict but also others in the work place. Self-esteem and ego are the two important aspects that effect our personal relationships, By just become aware of ego, it will dissipate soon and once you bring it into the light of consciousness, it will be unable to 'survive "People with low self-esteem are more socially anxious and shy which can make it difficult to form close relationships with others. The interplay between self-esteem and ego was analyzed and their effect on our day-to- day interactions and relationships was studied in this article.

Keywords: Influences, Self-Esteem, Ego, Daily Lives

At the most fundamental psychological level, there are three kinds of people one who inflate and encourage, or are more like a human vortex, a steady drain on emotional resources, couragebuilder or a spirit-sucker whom colleagues view as a burst of upbeat energy or a vitality-vampire, sucking the positive lifeblood out of co-workers or an ego-booster or an ego-buster. If Words and actions of a person contribute to the overall energy and happiness in himself and the lives of coworkers around him, he'll make a radical decision to positively reframe his outlook, speech and actions.

Ego -busters' vs. ego boosters’: Ego busters are destructive communication patterns and ego boosters are constructive communication patterns. The following are some of the characteristics of ego busters and how we can help those who use these destructive communication patterns, and can change these behaviors in our own speech.

1. Overwhelmingly Negative talk - For an organization to flourish, and not to stumble or experience flat growth, the people in key positions should inflate the morale of the key workers

\footnotetext{
${ }^{1}$ Health Education Officer, Central Health Education Bureau, New Delhi

*Responding Author

(C) 2016 I P Sampathirao; licensee IJIP. This is an Open Access Research distributed under the terms of the Creative Commons Attribution License (http://creativecommons.org/licenses/by/2.0), which permits unrestricted use, distribution, and reproduction in any Medium, provided the original work is properly cited.
} 


\section{The Influences of Self-Esteem \& Ego in Our Daily Life Lives}

with their positive speech. Quite often, these are the people who suffer from the ball-and-chain syndrome, where every task whether small or big is a humiliating drudgery, an impossible burden. Most of their day-to-day discussion is negative, pessimistic, sarcastic, hurtful, harmful, blame-ridden, and guilt-inducing.

If you yourself is indulging always in such talk (I can't) and filled with feelings of being a bad guy and just can't help it, it's high time to make a healthy change by striking a balance with choosing positive, optimistic, reassuring, encouraging, morale-building, forward-thinking (with "I can" words).If you hear some other person is engaged in such negative dialogue, first acknowledge by saying in a gentle manner that it seems he or she is really unhappy and frustrated and offer to share something positive. You can also remind him or her, the effect of such negative comments on your morale - and what you expect from him/he is to hear some of the positive contributions to the things going on around there.

2. playing blame-game - No one would like to know about the difference between our unwillingness to do or our inability to do a job. They're only interested in finding out what has been done or can be done. Experts agree that if every person involved in a task took a mere ten percent responsibility in a project's outcome (negative or positive), the work responsibility could be evenly distributed and shared. People who play the "blame game" lose on all accounts: They fail to function as a team player and lose their co-workers' respect. Playing the "blame game" is a career-killing move.

If you yourself is blaming the other and the task truly wasn't your responsibility, then you should share some useful information with the blame victim to that will help him to complete the task, otherwise, the blame culprit seem to be lazy, uncooperative and a non-team player. If he continues playing the same "blame game," no one will approach him with any new tasks as task assigning means trust. If some other person is blaming another, they can be asked "What can they do and what they are willing to do in such situation" In this way, blaming-throwing can go on indefinitely, so eliciting some information is better than none.

3. Grapevine Gossipers - If somebody thinks that he has nothing to talk about and at the same time omit all of the gossip in everyday speech, then he needs to be reassessed his communications. Gossip is damaging, especially in a work environment. True gossip should meet five essential criteria, 1.absence of person being talked about 2. The people having the conversation have an established relationship with the subject 3.The information has no direct impact on the lives of the people conducting the conversation 4. The conversation is generally negative in tone, and 5.The conversation is morality-based in its implications. However, the men and women gossip quite differently, while women gossip primarily to bond with one another, and men do it to bolster their self-esteem(1).

If you're the department's "gossip grapevine," try to cut your gossip by 10 percent. You'll soon find that it's easy to cut back on the time you spend "sharing news \& views" about co- 
workers and managers and realize that a gossiper is an "enabler" of negative relationships. When someone tries to share gossip about others defend the other person in their absence, just as you'd wish for others to defend you in your absence and remember, if a person gossips with you, he'll gossip about you!

4. Passive aggressive behavior - Perhaps the most difficult behavioral pattern to deal with is passive-aggressive behavior, it has an insidious role in interpersonal communications. This "I'm okay, but you're not okay" conduct can prove frustrating.

If you're the culprit in passive-aggressive conduct, you need to more carefully identify your needs. Don't expect positive responses from your negative inferences and sarcastic "off-thecuff” comments. Try to more articulately, concise and clearly state your needs. Those that fall into passive-aggressive behavior tend to take negative jabs in their speech and then follow it up with sweet comments. In order to deal with this type of conduct, you can ask the person to repeat any necessary information, deadlines, agreements, etc., and (face-to-face) agree to specified terms. Whatever you do, don't be sarcastic or attempt to "even the playing field" with similar negative comments, this will only serve to further "fuel the fire" in passive-aggressive individuals.

\section{Controlling Behaviour among controllers and micro managers.}

If you yourself happened to be a micro-manager, your core issue is lack of trust and if you don't trust people working with you they will not trust you. Let people set their own deadlines typically, they'll set shorter deadlines than you would and, as a result, they'll have a better attitude about their project and their own abilities.

When you find yourself working for a micro-manager, you need to start a positive communication campaign. Push a constant stream of communication out to your manager. Use phrases like: "This is where I am on this project, and unless I hear from you otherwise, I'll move forward to [Step B]." Send out a copious flow of updates and information, allowing the person to (slowly but surely) develop trust in your working relationship.

6. Playing Victim Mentality (a person who continually views the half-full glass as halfempty)this very damaging ego-busting behavior can spell "disaster" for a budding career. If you play yourself as "victim mentality," role realizes that you can irreparably damage your career. Using the "poor me" excuse in professional environs can make you seem ill equipped in handling undemanding situations, thereby allowing others to judge you completely incapable of managing more stressful and challenging situations. Realize that it serves no positive purpose to complain and moan, "The other department got all of the new computers... We never get any of the good stuff," type of speech. It merely brands you as the department's top grumbler, grouser and complainer. If you work with a person who continually views the half-full glass as halfempty, you'll need to assist them in moving their communications in a more positive direction. 


\section{The Influences of Self-Esteem \& Ego in Our Daily Life Lives}

7. Cyclops Syndrome - People who have “Cyclops Syndrome”, have one big "eye”- that is focused solely on themselves. This self-centered behavior stems from egocentric mentality, "It's all about me . . . enough about you ... now let's talk about me” it can also called as "oneupmanship” communication or “OOPS,” syndrome - or Our Own Personal Story (OOPS) syndrome. If you find yourself using "I "focused dialogue, it's time to reassess your focus on others. If cannot congratulate others on their victories, but rather use them as opportunity to build yourself up: Rather than saying "Oh, I already got a raise”, just say "Congratulations on your raise!” that will stop your egocentric speech patterns.

People suffering from the "Cyclops Syndrome” don’t allow others a moment in the spotlight and completely unaware of other's needs, they always have a better story, a bigger win or a more impressive development than anyone else (or OOPS - Our Own Personal Story). Self-centered Cyclops-sighted folks will always shift and bring the focus back on themselves: "Oh, you think you're having trouble on your ward, just wait until you hear mine," and "If you think your child is doing well in school, mine is doing better...”(2)

\section{Conflict at work place:}

The term passive aggression includes sarcasm, shifting blame, saying one thing while meaning another etc. Mr. X and Mr. Y are two colleagues locked in what seems to be an incurable conflict at work. Conflicts not only take a toll on our physical body (racing heartbeat etc.) but also it occupies our thoughts and causes a great deal of emotional distress. One rarely sees Mr. X and Mr Y more than a few feet from each other at work. The thought of Mr. Y increases Mr. Y's heart rate, while $\mathrm{X}$ 's thoughts do likewise every time $\mathrm{Y}$ is near. The way they look into one another's eyes tells their co-workers, Even their boss feels a bit awkward when the heat between them borders on the inappropriate. Conflictual behavior not only impacts those who are involved in the conflict but also those who have not part in it(3).

A colleague at work has a great dislike for you no matter how nice you are toward him. There may be a few specific reasons that he dislikes you, even though you have never done anything wrong toward him. More than likely your colleague is suffering from low self-esteem (and thus having a great ego). He could feel threatened by you. Maybe he perceives you as more successful than him, which causes jealousy. He will then notice unfavorable (in his eyes) aspects of you and recognizes them as pride, arrogance or impatience. He may see aspects or traits only that remind him of things he dislikes about himself. It could be that he believes that he was disliked by you, the reason might seem trivial, like for example, that you have overlooked him or made a face which he misinterpreted. It could also be a combination of the above mentioned factors. In essence, the main reason that your colleague dislikes you may be because of his inflated ego (unless you have really done something wrong against him)(4).

Self-esteem vs. Ego 


\section{The Influences of Self-Esteem \& Ego in Our Daily Life Lives}

There are two concepts that are important when it comes to personal relationships, namely selfesteem and ego. These are not synonyms, but are rather negatively correlated. The higher the self-esteem, the smaller is the ego. Self-esteem is an assessment of self-worth; how much or little value to you and to others. 'Self' concept is founded on a high self-esteem, self-beliefs (confident, honest, loyal) and they are helpful in actualizing the ideal 'self, as Maslow argues in his hierarchy of needs one needs high self-esteem to self-actualize and realize one's full potential. We tend to like people with a high self-esteem; it is common for these people to be happy, non-needy and selfless in listening to and helping others. We describe these people as "down to earth".

The ego is the opposite of self-esteem. Even though, ego has a number of definitions, the most commonly agreed definition is its self-defense mechanism and more importantly, a false concept. The entire ego concerned with indulging itself in self-destructive behaviours like authoritative demands from the people around them and differentiating them from others as the best and most competent persons, whether it is talking about other people behind their back out of their own insecurity or self-appraisal. The ego needs to be authenticated at all costs in order to 'survive' and if not it begins to weaken. The ego could even be likened to your inner child, constantly in need of attention and if it does not receive it lashes out(5).

Egocentricity is very common in the status conscious people in the authority. Men become idolized by their peers and this fuels their new addictions like smoking, alcohol, gambling women Pick UP. Most men are very egocentric when it comes to their dating lives to share their dating experiences with their male colleagues..This kind of behaviour can also be seen with materialistic people; buying more and more possessions to fuel their false self-concept to have everything to be impressed by the others and if don't have these 'things' others would treat you less of a person. Facebook has become a haven for the ego driven; statuses are often nothing but false self-esteem increasers with each person racking up 'likes' to differentiate themselves from others. The ego loves to feel what is called 'other nesses from others..Ultimately, the ego will try and protect itself at all costs in a "us vs. them" mentality. For instance, people with personal differences in a group unite against their common enemies. However, the ego can also be selfdestructive; it can make you feel worthless, lonely, depressed, and insignificant and all those other negative emotions.

\section{How to disconnect from ego:}

To disconnect from egoistic thinking and to move to a more internally authenticated, selfesteem-based way of thinking one has to re-direct his focus on himself, his 'true' and not his ego or what others may (or may not) think about him. One should be honest with himself, about his likes and dislikes and accepting them without any reservations. The ego is concerned with emphasizing strengths and de-emphasizing weaknesses. It is okay to 'love' your 'self', but it is not the same as inflated self-importance; what does you like about yourself that is of the most benefit to others (good listener) and what does you not like that you can work on (feeling 


\section{The Influences of Self-Esteem \& Ego in Our Daily Life Lives}

jealousy and how to minimize it. The difference between arrogance and confidence is arrogance is overcompensating for a known weakness; confidence knows your strengths and weaknesses to work on to improve them. There are a lot of people who prefer to 'hide' behind their strengths in fear that if they don't, their weaknesses will be revealed. To have weaknesses, it is okay, it means be a human. When caught with egocentric thoughts, be in present and don't judge or condemn the thought,(lest it will push back) and just become aware of it, it will soon dissipate, once you bring it into the light of consciousness, the ego is unable to 'survive"(6).

\section{You are not your thoughts.}

When you become aware of these habitual thought patterns, you begin to become more selfaware of your ego and more importantly, how you can weaken it. In the story of 'Two Wolves', where an old grandfather teaches his grandson about life, "A fight is going on inside me" he said to the boy."It is a terrible fight and it is between two wolves. One is evil - he is anger, envy, sorrow, regret, greed, arrogance self-pity, guilt, resentment, inferiority, lies, false pride, superiority, and the other is my own ego". The other is good - he is joy, peace, love, hope, serenity, humility, kindness, benevolence, empathy, generosity, truth, compassion, and faith. The same fight is going on inside you -and inside every other person, too.”The grandson thought about it for a minute and then asked his grandfather, "Which wolf will win?”'The old grandfather simply replied, "The one you feed."

You may be dealing with a person with low self-esteem, so a good idea could be to feed his ego. There are basically three ways of doing this: You can tell a mutual friend or colleague that you really like, admire, and respect the critical person. The reason you should do this through a third person is that when the message reaches your troublesome colleague, it will be more strong and believable than if it came directly from you. The reason this might work is that it is psychologically difficult to dislike someone who likes you. Ask the person to do you a favor. It seems counterintuitive, but people tend to form more favorable impressions of people they help, than of people who help them. Tell this person something embarrassing about yourself. This way you will become less threatening to this person.

\section{Defense Mechanisms and their affect on communication:}

Sigmund Freud describes how the Ego uses a range of mechanisms to handle the conflict between the Id, the Ego and the Super ego.

Anxiety and tension: Freud noted that a major drive for most people is the reduction in tension, and that a major cause of tension was anxiety. He identified three different types of anxiety.

Reality Anxiety: Freud noted that a major drive for most people is the reduction in tension, and that a major cause of tension was anxiety. He identified three different types of anxiety. 


\section{The Influences of Self-Esteem \& Ego in Our Daily Life Lives}

Reality Anxiety: This is the most basic form of anxiety and is typically based on fears of real and possible events, such as being bitten by a dog or falling from a ladder. The most common way of reducing tension from Reality Anxiety is taking oneself away from the situation, running away from the dog or simply refusing to go up the ladder.

Neurotic Anxiety: This is a form of anxiety which comes from an unconscious fear that the basic impulses of the ID (the primitive part of our personality) will take control of the person, leading to eventual punishment (this is thus a form of Moral Anxiety).

Moral Anxiety: This form of anxiety comes from the Superego in the form of a fear of violating values and moral codes, and appears as feelings of guilt or shame. This is the most basic form of anxiety and is typically based on fears of real and possible events, such as being bitten by a dog or falling from a ladder. The most common way of reducing tension from Reality Anxiety is taking oneself away from the situation, running away from the dog or simply refusing to go up the ladder.

The problem with the ego is it can often 'disguise' itself into self-esteem and it is important to become aware of this behaviour when it arises.

Unacceptable drives or urges do not disappear; they continue to exert a powerful influence on behavior. The forces, which try to keep painful or socially undesirable thoughts and memories out of the conscious mind, are termed defense mechanisms. There is a perpetual battle between the wish (repressed into the id) and the defense mechanisms.

We use defense mechanisms to protect ourselves from feelings of anxiety or guilt, which arise because we feel threatened, or because our id or superego becomes too demanding. They are not under our conscious control, and are non-voluntaristic. With the ego, our unconscious will use one or more to protect us when we come up against a stressful situation in life. Ego-defense mechanisms are natural and normal. When they get out of proportion, neuroses develop, such as anxiety states, phobias, obsessions, or hysteria. Freud's defense mechanisms can be applied to pride, ego, and self-esteem (7).

When anxiety occurs, the mind first responds by an increase in problem-solving thinking, seeking rational ways of escaping the situation. If this is not fruitful (and maybe anyway), a range of defense mechanisms may be triggered. These are tactics which the Ego develops to help deal with the Id and the Super Ego. All Defense Mechanisms share two common properties i.e., appear unconsciously and tend to distort, transform, or otherwise falsify reality. In distorting reality, there is a change in perception which allows for a lessening of anxiety, with a corresponding reduction in felt tension.

Compensation is the process of masking perceived negative self-concepts by developing positive self-concepts to make up for and to cover perceived negative self-concepts, 


\section{The Influences of Self-Esteem \& Ego in Our Daily Life Lives}

Denial is the subconscious or conscious process of blinding yourself to negative selfconcepts that you believe exist in you, but that you do not want to deal with or face. It is "closing your eyes" to your negative self-concepts about people, places, or things that you find too severe to deal with. Smokers may believe that smoking is not injurious to health.

Displacement is when you express feelings to a substitute target, because you are unwilling to express them to the real target. The feelings expressed to the substitute target are based on your negative self-concepts about the real target and yourself in relation to the real target. That is, you think poorly of someone and of yourself in relation to them.

Identification as a defense mechanism is the identification of yourself with causes, groups, heroes, leaders, movie stars, organizations, religions, sports stars, or whatever you perceive as being good self-concepts or self-images. This is a way to think of yourself as good self-concepts or images.

Introjection is the acceptance of the standards of others to avoid being rated as negative selfconcepts by their standards. For example, you may uncritically accept the standards of your government or religion in order to be accepted as good self-concepts by them. Introjection can be considered as the extreme case of conformity, because introjection involves conforming your beliefs as well as your behaviors. So-called educational systems prey upon this defense mechanism to produce parrots to spread their dogmas as if they were factual and superior.

Projection is the attribution to others of your own negative self-concepts. This occurs when you want to avoid facing negative self-concepts about your behaviors or intentions, and you do so by seeing them, in other people, instead. For example you may hate someone, but your super ego reminds you that such a hatred is unacceptable. You will adjust it by thinking that they also hate you.

Rationalization is the process of explaining why, this time, you do not have to be judged as negative self-concepts because of your behaviors or intentions. That is, you justify and excuse your misdeeds or mistakes with reasons that are circumstantial at best and unfounded at worst. Rationalization is also referred to as the "sour grapes" response.

Reaction formation is the process of developing conscious positive self-concepts in order to cover and hide opposite, negative self-concepts. It is the making up for negative self-concepts by showing off their reverse.

Regression is the returning to an earlier time in your life when you were not so threatened with becoming negative self-concepts. You return to thoughts, feelings, and behaviors of an earlier developmental stage in order to identify yourself as you used to back then. 


\section{The Influences of Self-Esteem \& Ego in Our Daily Life Lives}

Repression is the unconscious and seemingly involuntary removal from awareness of the negative self-concepts that your ego finds too painful to tolerate. For example, during Oedipus complex about the same sex parents are repressed.

Ritual and undoing as a defense mechanism is the process of trying to undo negative selfconcept ratings of yourself by performing rituals or behaviors designed to offset the behaviors that the negative ratings of you were based on.

Sublimation is the process of diverting your feelings about the negative self-concepts that you have of yourself or others into more socially acceptable activities.

\section{Self-esteem and self-disclosure}

The use of social media for self-disclosure has shown to be very helpful for those with low selfesteem. People with low self-esteem are more socially anxious and shy which can make it difficult to form close relationships with others. This can harm both their physical and mental health because feeling connected to others is considered a fundamental human motivation. Individuals with low self-esteem have difficulty disclosing to others because they are very focused on not revealing their flaws and fear criticism and disapproval from others. Disclosing less, therefore, protects them from the possibility of rejection or being ignored. In light of these fears, social media can provide a safe environment for people with low self-esteem to disclose personal information because they cannot see their partner's reactions which can help them to more freely express themselves.(8)

While many with low self-esteem view social media as a safe outlet for disclosure, many do not receive positive feedback for their disclosures. People with low self-esteem tend to post more negative thoughts on social media which has been shown to make them less liked by readers. Negative posts are also more likely to be ignored by readers in hopes that the discloser will stop and begin to post more positively. When someone who frequently shares negative thoughts posts something positive they do receive more positive feedback from readers. In contrast, someone with high self-esteem is more liked by readers and tends to post more positively. If they do post something negative they tend to get more responses than those with low self-esteem do (8).

\section{CONCLUSION:}

Our Egos are fed and kept alive by our thoughts and emotions. It is like a parasite that needs constant attention in order to survive, but it will never be fully satisfied. It is like a parasite that needs constant attention in order to survive. people guide their actions based off of what they think is correct when trying to match their identity. Some people, more easily dismiss opposing ideas that do not fit into their model of perceived reality about who they are and are not. Often people in power exert strong social pressure over others by influencing them with their beliefs. Our collective societal Egos try to keep people in the roles that make most sense to us against fear of the Unknown (9). 


\section{REFERENCES:}

1. A nationwide study conducted by a UK group, Industrial Society, 2001

2. Dr. Susanne Gaddis, www.CommunicationsDoctor.com

3. Excel at life Monica A. Frank, Ph. D, https://www.excelatlife.com/articles/crazymakers.htm.

4. How to cope with the colleague who dislike you: By Joachim Vogt Isaksen, http://www.popularsocialscience.com/2012/12/05/how-to-cope-with-the-colleaguewho-dislikes-you/

5. The ego vs self-esteem, by Sam Thomas Davies 10 Comments

6. Eckhart Tolle's 'The Power of Now

7. Freud's defense mechanisms, by Saul McLeodpublished 2008, simply psychology.

8. Forest, Amanda L.; Wood, Joanne V. (2012). "When Social Networking is Not Working: Individuals with Low Self-Esteem Recognize but do not Reap the Benefits of Self-Disclosure on Facebook". Psychological Science 23 (3): 298-302.

9. Eckhart Tolle in his book A New Earth

How to cite this article: P Sampathirao (2016), The Influences of Self-Esteem \& Ego in Our Daily Life, International Journal of Indian Psychology, Volume 3, Issue 3, No. 6, DIP: 18.01.106/20160303 